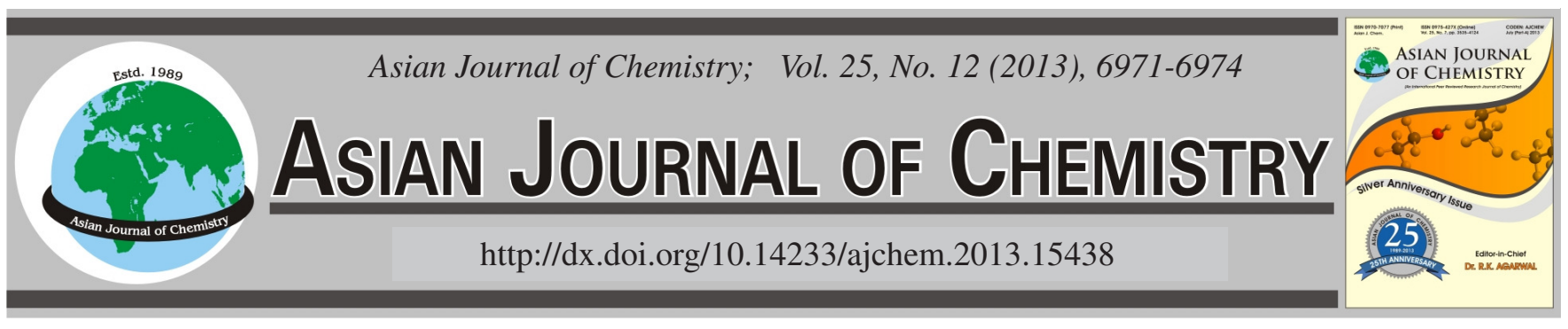

\title{
Synthesis and Crystal Structure of Tetranuclear Nickel Complex Derived from a N-(3-Methoxy-2-hydroxybenzyl)glycine Ligand
}

\author{
Bo-Wen Wang, Yu-Qin Ma*, Ying-Gao, Gui-MiaoYu, Hui-Yu Wang and Yun-Hui Li
}

Changchun University of Science and Technology, Changchun 130022, P.R. China

*Corresponding author: Fax: +86 0431-85308866; Tel: +86 0431-85308866; E-mail: myq9393@ sina.com

\begin{abstract}
A tetranuclear nickel(II) complex featuring defective double-cubane of formula, $\left[\mathrm{Ni}_{4}\left(\mathrm{~L}_{2}{ }_{2}\left(\mathrm{C}_{12} \mathrm{H}_{8} \mathrm{~N}_{2}\right)_{2}\left(\mathrm{CH}_{3} \mathrm{O}\right)_{2}\left(\mathrm{H}_{2} \mathrm{O}\right)_{2}\right]\left(\mathrm{ClO}_{4}\right)_{2}(\mathbf{1})\right.$, where $\mathrm{H}_{2} \mathrm{~L}$ is $\mathrm{N}$-(3-methoxy-2-hydroxybenzyl)glycine has been prepared and structurally characterized. The structure of complex 1 consists of one $\left[\mathrm{Ni}_{4}(\mathrm{~L})_{2}\left(\mathrm{C}_{12} \mathrm{H}_{8} \mathrm{~N}_{2}\right)_{2}\left(\mathrm{CH}_{3} \mathrm{O}\right)_{2}\left(\mathrm{H}_{2} \mathrm{O}\right)_{2}\right]^{2+}$ cation and two perchlorate anions. The vertices of the two face-sharing defective cubanes are occupied by alternating nickel and oxygen ions and the four $\mathrm{Ni}(\mathrm{II})$ ions in the cluster are held together by two bridging $\mu_{3}-\mathrm{CH}_{3} \mathrm{O}^{-}$ions and four $\mu_{2}-\mathrm{O}^{-}$ions from two $\mathrm{L}^{2-}$ ligands, forming a planar $\mathrm{Ni}_{4}$ parallelogram. The complex $\mathbf{1}$ is further stabilized via intramolecular hydrogen bonds, generating a dimeric unit.
\end{abstract}

Key Words: Nickel complex, Crystal structure, Tetranuclear.

\section{INTRODUCTION}

The design and synthesis of metal-organic coordination polymers have received considerable attention because of their fascinating self-assembled structures and potential applications in magnetic ${ }^{1}$ and enzyme catalytic processes ${ }^{2}$. The recent development of self-assembled supramolecular chemistry can rationally design and synthesize metal-organic coordination polymers depending on the ligand geometry and coordination propensity of the metal ion. Organic ligands formed by reaction between the amino acids and aldehydes are good candidates to construct metal clusters. More and more geometrically intriguing supramolecular structures derived from such ligands, for example, capsules ${ }^{3}$, helices ${ }^{4}$ and polynuclear clusters with different numbers of metal ions ${ }^{5,6}$ have been successfully obtained.

Structural studies on the amino acid Schiff bases reveal that they can act as tridentate moiety, coordinating to metal centers through the phenolato-O, imine- $\mathrm{N}$ and carboxyl-O with suitable relative positions ${ }^{7}$. The stability of the Schiff base products isolated depends on factors such as the amino acid side chain polarity ${ }^{8}$, the metal, temperature ${ }^{9}$, etc. However, Casella Gullotti ${ }^{8}$ found that Schiff bases between amino acids with nonpolar side chains were unstable upon coordination to some transition metal. The problems with ligand instability can be overcome by reduction of the Schiff base to give an amine, because of greater flexibility arising from reduction of the azo methyene $(-\mathrm{CH}=\mathrm{N}-)$ group, appear to serve as better models in this respect ${ }^{10,11}$. Though the flexibility to the ligand skeleton is offered by the $-\mathrm{CH}_{2}-\mathrm{NH}$ - moiety, the formation of the final basic structure is guided by the flexibility introduced by the methylene moiety in the side chain of the ligands ${ }^{12,13}$. This prompted us to investigate the role of a simple side chain such as $-\mathrm{CH}_{2} \mathrm{COOH}$ in reduced Schiff base ligand on the self-assembly of coordination polymers.

In this communication, we have investigated a new reduced Schiff base ligand derived from $o$-vanillin and glycine, i.e. N-(3-methoxy-2-hydroxybenzyl)glycine $\left(\mathrm{H}_{2} \mathrm{~L}\right)$. The reaction of this ligand with $\mathrm{Ni}\left(\mathrm{ClO}_{4}\right)_{2} \cdot 6 \mathrm{H}_{2} \mathrm{O}$ in presense of the 1,10-phenanthroline in methanol produces a novel tetranuclear $\mathrm{Ni}$ (II) complex with defective double-cubane core, representing the first structurally characterized metal complex of this versatile ligand.

\section{EXPERIMENTAL}

All the reagents and solvents employed were commercially available and used as received without further purification. The $\mathrm{H}_{2} \mathrm{~L}$ ligand is prepared in a similar manner according to the reported procedures ${ }^{14}$. Elemental analysis for $\mathrm{C}, \mathrm{N}$ and $\mathrm{H}$ were performed with a Perkin-Elmer 2400 II analyzer.

Preparation of complex 1: The reduced Schiff base ligand $\left(\mathrm{H}_{2} \mathrm{~L}\right)$ derived from $o$-vanillin and glycine was prepared in a similar manner according to the reported procedures ${ }^{10,15}$.

To a solution of glycine $(10 \mathrm{mmol})$ in water $(10 \mathrm{~mL})$ containing $\mathrm{NaOH}(0.40 \mathrm{~g}, 10 \mathrm{mmol})$ was added $o$-vanillin $(1.55 \mathrm{~g}$, $10 \mathrm{mmol})$ in ethanol $(10 \mathrm{~mL})$. The yellow solution was stirred 
for $1 \mathrm{~h}$ at room temperature prior to cooling in an ice bath. The intermediate Schiff base that had formed was reduced with an excess of sodium borohydride $(0.46 \mathrm{~g}, 12 \mathrm{mmol})$ in water $(5 \mathrm{~mL})$ containing a few drops of sodium hydroxide solution. The yellow colour was slowly discharged and after 10 min the solution was acidified with concentrated hydrogen chloride to a $\mathrm{pH}$ of 5-6. The resulting white solid was filtered off, washed with dry methanol and then diethyl ether, dried and recrystallized from water/ethanol (1:1). Yield was $1.62 \mathrm{~g}$ $(53 \%)$.

The title complex was synthesized by adding $\mathrm{Ni}\left(\mathrm{ClO}_{4}\right)_{2} \cdot 6 \mathrm{H}_{2} \mathrm{O}(36.5 \mathrm{mg}, 0.1 \mathrm{mmol})$ and 1,10-phenanthroline monohydrate $(9.9 \mathrm{mg}, 0.05 \mathrm{mmol})$ to a solution of $\mathrm{H}_{2} \mathrm{~L}$ (21.1 $\mathrm{mg}, 0.1 \mathrm{mmol})$ and $\mathrm{LiOH}(0.20 \mathrm{mmol})$ in $10 \mathrm{~mL}$ of methanol. The resulting mixture was stirred for $5 \mathrm{~h}$ at room temperature to afford a green solution, which was left unperturbed to allow the slow evaporation of the solvent. Green single crystals suitable for X-ray diffraction analysis were formed after about three weeks. Yield was $8.1 \mathrm{mg}(24.7 \%$ based on metal salt).

X-Ray crystallography: Crystallographic data were collected on a Bruker Apex II CCD diffractometer with graphite monochromated Mo $\mathrm{K}_{\alpha}$ radiation $(\lambda=0.71073 \AA)$ at a temperature of $185 \mathrm{~K}$, for $\mathbf{1}$. Data processing was accomplished with the SAINT processing program. These structures were solved by the direct methods and refined on $\mathrm{F}^{2}$ by full-matrix least squares using SHELXTL97 ${ }^{16,17}$. The location of Ni atom was easily determined and $\mathrm{O}, \mathrm{N}$ and $\mathrm{C}$ atoms were subsequently determined from the difference Fourier maps. All non-hydrogen atoms were refined with anisotropic thermal parameters. Crystallographic data and refinement details of $\mathbf{1}$ are listed in Table1. CCDC-922289 contain the supplementary crystallographic data for this paper. These data can be obtained free of charge from the Cambridge Crystallographic Data Centre via www.ccdc.cam.ac.uk/data_request/cif. [or from the Cambridge Crystallographic Data Centre (CCDC), 12 Union Road, Cambridge CB2 1EZ, UK; fax: (44) 1223-336033; email: deposit@ccdc.ccam.ac.uk].

\section{RESULTS AND DISCUSSION}

The molecular structure of title complex $\mathbf{1}$ is illustrated in Fig. 1. Selected bond distances and angles are given in Table-2. The asymmetric unit consists of one $\left[\mathrm{Ni}_{4}(\mathrm{~L})_{2}\left(\mathrm{C}_{12} \mathrm{H}_{8} \mathrm{~N}_{2}\right)_{2}\left(\mathrm{CH}_{3} \mathrm{O}\right)_{2}\left(\mathrm{H}_{2} \mathrm{O}\right)_{2}\right]^{2+}$ cation and two perchlorate anions. The four $\mathrm{Ni}(\mathrm{II})$ ions in the cluster are held together by two bridging $\mu_{3}-\mathrm{CH}_{3} \mathrm{O}^{-}$ions (O9 and $\mathrm{O} 10$ ) and four $\mu_{2}-\mathrm{O}^{-}$ ions (O1, O3, O5 and $\mathrm{O} 7)$ from two $\mathrm{L}^{2-}$ ligands forming a planar $\mathrm{Ni}_{4}$ parallelogram. The maximum displacements from the least-squares plane through $\mathrm{Ni} 1, \mathrm{Ni} 2, \mathrm{Ni} 3$ and $\mathrm{Ni} 4$ are $-0.0507(6)$ and $-0.0512(6) \AA$ for atoms Ni2 and Ni3, respectively. Two $\mu_{3}-\mathrm{CH}_{3} \mathrm{O}^{-}$ligands bridge the four $\mathrm{Ni}^{2+}$ ions displaced above 1.0610(28) and below -1.3062(28) $\AA$ the $\mathrm{Ni}_{4}$ plane. The $\mathrm{Ni} \cdots \mathrm{Ni}$ distances are in the range $3.1287(8)$ 3.2036(9) $\AA$, like that observed in reported similar tetranuclear nickel clusters ${ }^{18}$. The $\mathrm{Ni} 2$ and $\mathrm{Ni} 3$ exhibit the same $\mathrm{N}_{3} \mathrm{O}_{3}$ coordination sphere, which was completed by a chelating $\mathrm{L}^{2-}$ ligand (terminal acetate $\mathrm{O}$ atom, phenolate $\mathrm{O}$ atom and the secondary amino $\mathrm{N}$ atom), 1,10-phenanthroline (two $\mathrm{N}$ atoms) and $\mu_{3}-\mathrm{CH}_{3} \mathrm{O}^{-}$ions. The coordination spheres of the Ni1 and

\begin{tabular}{|c|c|}
\hline \multicolumn{2}{|c|}{$\begin{array}{c}\text { TABLE-1 } \\
\text { CRYSTALLOGRAPHIC DATA FOR COMPOUND } 1\end{array}$} \\
\hline Complex & 1 \\
\hline Formula & $\mathrm{C}_{46} \mathrm{H}_{48} \mathrm{~N}_{6} \mathrm{Ni}_{4} \mathrm{O}_{20} \mathrm{Cl}_{2}$ \\
\hline $\mathrm{Mr}$ & 1310.64 \\
\hline Cryst size $[\mathrm{mm}]$ & $0.19 \times 0.17 \times 0.15$ \\
\hline Colour & green blocks \\
\hline Cryst. syst. & Triclinic \\
\hline Space group & $\mathrm{P} \overline{1}$ \\
\hline $\mathrm{T}[\mathrm{K}]$ & $185(2)$ \\
\hline $\mathrm{a}[\AA]$ & $13.26(9)$ \\
\hline $\mathrm{b}[\AA]$ & $13.31(10)$ \\
\hline $\mathrm{c}[\AA]$ & $16.12(12)$ \\
\hline$\alpha[\operatorname{deg}]$ & $80.66^{\circ}(10)$ \\
\hline$\beta[\mathrm{deg}]$ & $87.68^{\circ}(10)$ \\
\hline$\gamma[\mathrm{deg}]$ & $68.11^{\circ}(10)$ \\
\hline $\mathrm{V}\left[\AA^{3}\right]$ & $2595.5(3)$ \\
\hline $\mathrm{Z}$ & 2 \\
\hline $\mathrm{D}_{\text {calcd }}\left[\mathrm{g} \mathrm{cm}^{-3}\right]$ & 1.677 \\
\hline$\mu\left(\mathrm{Mo} \mathrm{K}_{\alpha}\right)\left[\mathrm{mm}^{-1}\right]$ & 1.615 \\
\hline $\mathrm{F}(000)$ & 1344 \\
\hline Reflns collected & 14409 \\
\hline Unique reflns & 10102 \\
\hline $\mathrm{R}_{\mathrm{int}}$ & 0.0258 \\
\hline Parameters/restraints & $707 / 0$ \\
\hline GOF & 1.040 \\
\hline $\mathrm{R} 1[\mathrm{I}>2 \sigma(\mathrm{I})]$ & 0.0525 \\
\hline wR2 (all data) & 0.1443 \\
\hline Largest diff. peak/hole [e $\AA^{-3}$ ] & 1.160 and -0.599 \\
\hline
\end{tabular}

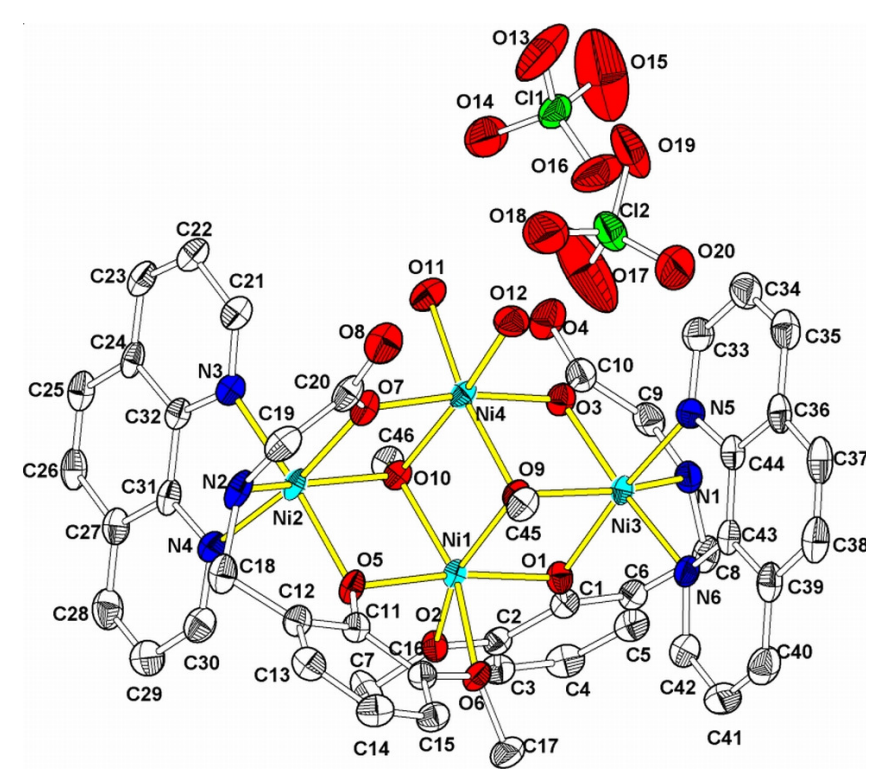

Fig. 1. A view of the complex $\mathbf{1}$, showing the atomic numbering scheme. Hydrogen atoms have been removed for clarity. Thermal ellipsoids are at $30 \%$ probability level

$\mathrm{Ni} 4$ are completed by two methoxy group of $\mathrm{L}^{2-}$ ligands (O1 and O6) for Ni1 and two water molecules for $\mathrm{Ni} 4$, respectively, generating six-coordinate centres with a distorted octahedral environment.

The successful reduction of the imine is evident from the N1-C8 and N2-C18 (1.475(6), 1.496(7) A) distances when compared with the distance seen for related glycine- $O$-vanillin complex $(1.241(7) \AA)^{19}$. Further, the distances for N1-C9, 


\begin{tabular}{|c|c|c|c|}
\hline \multicolumn{4}{|c|}{$\begin{array}{c}\text { TABLE-2 } \\
\text { SELECTED BOND LENGTHS }(\AA) \text { AND } \\
\text { ANGLES }\left({ }^{\circ}\right) \text { FOR COMPLEX } 1\end{array}$} \\
\hline Ni1-O1 & $1.967(3)$ & Ni2-O5 & $2.008(3)$ \\
\hline Ni1-O5 & $1.980(3)$ & Ni2-O7 & $2.029(3)$ \\
\hline Ni1-O10 & $2.048(3)$ & Ni2-O10 & $2.144(3)$ \\
\hline Ni1-O9 & $2.054(3)$ & Ni2-N3 & $2.008(4)$ \\
\hline Ni1-O6 & $2.173(3)$ & $\mathrm{Ni2}-\mathrm{N} 4$ & $2.093(4)$ \\
\hline $\mathrm{Ni1}-\mathrm{O} 2$ & $2.202(3)$ & $\mathrm{Ni2}-\mathrm{N} 2$ & $2.103(4)$ \\
\hline Ni3-O1 & $2.009(3)$ & $\mathrm{Ni4}-\mathrm{O} 3$ & $2.039(3)$ \\
\hline Ni3-O9 & $2.122(3)$ & $\mathrm{Ni4}-\mathrm{O} 7$ & $2.043(4)$ \\
\hline $\mathrm{Ni3}-\mathrm{O} 3$ & $2.010(3)$ & $\mathrm{Ni} 4-\mathrm{O} 9$ & $2.055(3)$ \\
\hline Ni3-N1 & $2.093(4)$ & Ni4-O10 & $2.069(3)$ \\
\hline Ni3-N5 & $2.090(4)$ & Ni4-O11 & $2.088(3)$ \\
\hline Ni3-N6 & $2.072(4)$ & $\mathrm{Ni4}-\mathrm{O} 12$ & $2.091(3)$ \\
\hline O1-Ni1-O5 & 171.44(13) & O5-Ni1-O6 & $77.45(12)$ \\
\hline O1-Ni1-O10 & 107.14(13) & O10-Ni1-O6 & $157.85(12)$ \\
\hline O5-Ni1-O10 & $81.00(13)$ & O9-Ni1-O6 & $95.05(12)$ \\
\hline O1-Ni1-O9 & $80.06(12)$ & $\mathrm{O} 1-\mathrm{Ni1}-\mathrm{O} 2$ & $75.89(12)$ \\
\hline O5-Ni1-O9 & $103.68(13)$ & O5-Ni1-O2 & $101.17(12)$ \\
\hline O9-Ni1-O10 & $85.04(13)$ & O10-Ni1-O2 & $94.88(12)$ \\
\hline O1-Ni1-O6 & $94.65(13)$ & O9-Ni1-O2 & $154.80(12)$ \\
\hline O6-Ni1-O2 & $94.28(12)$ & O1-Ni3-O3 & $96.20(13)$ \\
\hline O5-Ni2-O7 & $99.46(13)$ & O1-Ni3-N6 & $92.21(15)$ \\
\hline O5-Ni2-N3 & $167.35(14)$ & O3-Ni3-N6 & $169.94(15)$ \\
\hline O7-Ni2-N3 & $90.86(14)$ & O1-Ni3-N5 & $170.66(15)$ \\
\hline O5-Ni2-N4 & $89.86(14)$ & O3-Ni3-N5 & $92.11(15)$ \\
\hline O7-Ni2-N4 & $170.65(14)$ & N6-Ni3-N5 & 79.12(16) \\
\hline N3-Ni2-N4 & $79.80(16)$ & O1-Ni3-N1 & $89.02(14)$ \\
\hline $\mathrm{O} 5-\mathrm{Ni} 2-\mathrm{N} 2$ & $90.11(14)$ & O3-Ni3-N1 & $81.33(15)$ \\
\hline $\mathrm{O} 7-\mathrm{Ni2}-\mathrm{N} 2$ & $80.16(15)$ & N6-Ni3-N1 & $104.38(16)$ \\
\hline N3-Ni2-N2 & $98.89(15)$ & N5-Ni3-N1 & $96.44(16)$ \\
\hline N4-Ni2-N2 & $100.65(17)$ & O1-Ni3-O9 & $77.50(12)$ \\
\hline O5-Ni2-O10 & $78.05(12)$ & O3-Ni3-O9 & 79.47(12) \\
\hline O7-Ni2-O10 & 77.92(12) & N6-Ni3-O9 & $97.06(14)$ \\
\hline N3-Ni2-O10 & $97.19(13)$ & N5-Ni3-O9 & 99.94(14) \\
\hline N4-Ni2-O10 & $103.59(13)$ & N1-Ni3-O9 & $155.10(14)$ \\
\hline N2-Ni2-O10 & $152.89(14)$ & O3-Ni4-O7 & $171.40(13)$ \\
\hline O9-Ni4-O10 & $84.47(12)$ & O3-Ni4-O9 & $80.40(12)$ \\
\hline $\mathrm{O} 3-\mathrm{Ni4}-\mathrm{O} 11$ & 87.13(14) & O7-Ni4-O9 & $92.47(12)$ \\
\hline O7-Ni4-O11 & $99.81(14)$ & $\mathrm{O} 3-\mathrm{Ni} 4-\mathrm{O} 10$ & $95.07(13)$ \\
\hline O9-Ni4-O11 & $167.43(13)$ & $\mathrm{O} 7-\mathrm{Ni} 4-\mathrm{O} 10$ & $79.35(12)$ \\
\hline $\mathrm{O} 3-\mathrm{Ni} 4-\mathrm{O} 12$ & $96.88(14)$ & O10-Ni4-O11 & $95.12(13)$ \\
\hline
\end{tabular}

C6-C8, N2-C19 and C12-C18 (1.471(6), 1.504(7), 1.464(6) and 1.501(7) $\AA$, respectively) are typical of single bonds, being significantly longer than those of imine complex and indicating the loss of conjugation. The angles centered about $\mathrm{N} 1$ and $\mathrm{N} 2$ are consistent with an $s p^{3}$ tetrahedral $\mathrm{N}$ and are similar to those for this general class of $\mathrm{N}$-(o-hydroxybenzyl)glycine ligand in $\left[\mathrm{Cu}_{2}\left(\mathrm{C}_{9} \mathrm{H}_{9} \mathrm{O}_{3} \mathrm{~N}\right)_{2}\left(\mathrm{H}_{2} \mathrm{O}\right)\right]_{\mathrm{n}} \cdot \mathrm{nH}_{2} \mathrm{O}^{20}$ and $\left[\mathrm{Cu}\left(\mathrm{C}_{9} \mathrm{H}_{10} \mathrm{O}_{3} \mathrm{~N}\right)\left(\mathrm{C}_{10} \mathrm{H}_{8} \mathrm{~N}_{2}\right)\right]_{\mathrm{n}} \mathrm{Cl}_{\mathrm{n}} \cdot \mathrm{nH}_{2} \mathrm{O}^{21}$ complexes.

In the crystal structure of complex $\mathbf{1}$, the uncoordinated perchlorate anions are involved in forming intermolecular hydrogen bonds. Two adjacent nickel clusters participate in

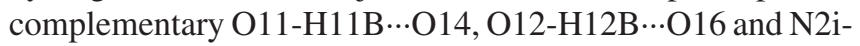
$\mathrm{H} 2 \mathrm{~A} \cdots \mathrm{O} 13$ hydrogen bonds forming a dimeric structure [symm code: (i) 1 - x, 2 - y, 1 -z] (Fig. 2 and Table-3). In addition,

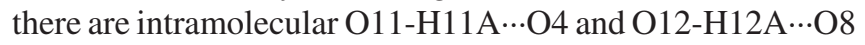
hydrogen bonds in complex $\mathbf{1}$ between the water molecules and carboxylate groups of the ligands.

\begin{tabular}{|c|c|c|c|c|}
\hline \multicolumn{5}{|c|}{$\begin{array}{c}\text { TABLE-3 } \\
\text { INTRA- AND INTERMOLECULAR } \\
\text { HYDROGEN BONDS FOR COMPLEX } 1\end{array}$} \\
\hline D-H $\cdots A$ & $\mathrm{~d}(\mathrm{D}-\mathrm{H})$ & $\mathrm{d}(\mathrm{H} \cdots \mathrm{A})$ & $\mathrm{d}(\mathrm{D} \cdots \mathrm{A})$ & $\angle$ (DHA) \\
\hline $\mathrm{N} 22^{\mathrm{i}}-\mathrm{H} 2 \mathrm{~A} \cdots \mathrm{O} 13$ & 0.91 & 2.19 & $3.057(6)$ & 159.1 \\
\hline 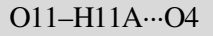 & 0.85 & 1.91 & $2.756(6)$ & 171.0 \\
\hline 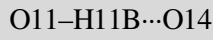 & 0.85 & 2.12 & $2.967(6)$ & 171.3 \\
\hline $\mathrm{O} 12-\mathrm{H} 12 \mathrm{~A} \cdots \mathrm{O} 8$ & 0.85 & 1.89 & $2.728(6)$ & 167.1 \\
\hline $\mathrm{O} 12-\mathrm{H} 12 \mathrm{~B} \cdots \mathrm{O} 16$ & 0.85 & 2.06 & $2.896(7)$ & 167.4 \\
\hline
\end{tabular}

\section{Conclusion}

To summarize, a novel $\mathrm{Ni}_{4}{ }_{4}$ complex featuring defective double-cubane has been prepared by using the reduced Schiff base ligand $\left(\mathrm{H}_{2} \mathrm{~L}\right)$. The reduction of the ligand increases donor strength of the internal nitrogen donors and also generates the methylene with an increased torsional strain, which further increases ligand flexibility. Both chelating and bridging capacities of this quadridentate Schiff-base ligand consolidate this $\mathrm{Ni}_{4}$ cluster.

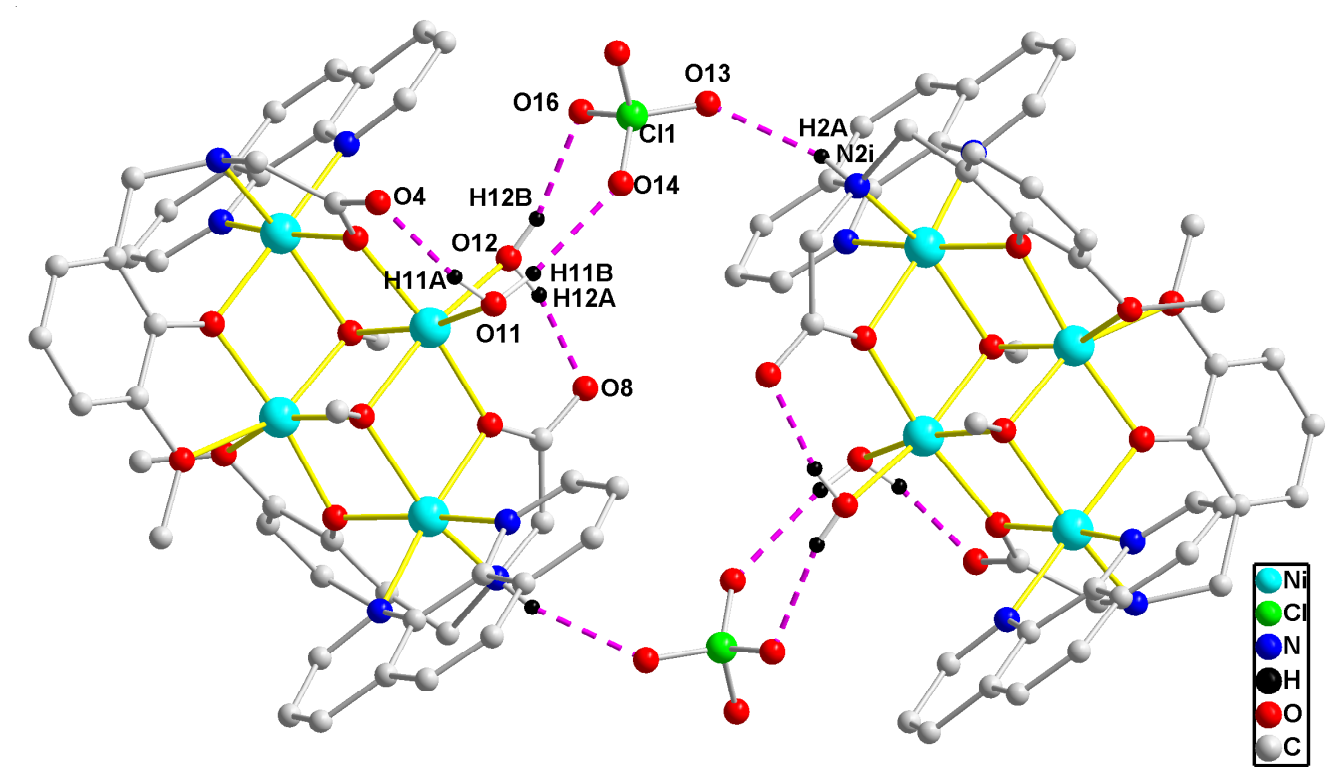

Fig. 2. The dimeric structure of the complex 1, with hydrogen bonds shown as dashed lines 


\section{ACKNOWLEDGEMENTS}

The authors thank the project supported by the Development and Reform Commission of Jilin Province, the Science and Technology Bureau of Changchun City, the Science and Technology Department of Jilin Province, China (2011174) and Changchun University of Science and Technology for their financial support.

\section{REFERENCES}

1. E.C. Yang, W. Wernsdorfer, S. Hill, R.S. Edwards, M. Nakano, S. Maccagnano, L.N. Zakharov and D.N Hendrickson, Polyhedron, 22, 1727 (2003).

2. H. Carlsson, M. Haukka, A. Bousseksou, J.M. Latour and E. Nordlander, Inorg. Chem., 43, 8252 (2004).

3. M.A. Alam, M. Nethaji and M. Ray, Angew. Chem. Int. Ed., 42, 1940 (2003).

4. B. Sreenivasulu and J.J. Vittal, Angew. Chem. Int. Ed., 43, 5769 (2004).

5. A. Das, F.J. Klinke, S. Demeshko, S. Meyer, S. Dechert and F. Meyer, Inorg. Chem., 51, 8141 (2012).

6. S.Y. Zhang, W.Q. Chen, B. Hu, Y.M. Chen, W. Li and Y.H. Li, Inorg. Chem. Commun., 16, 74 (2012).

7. B. Baruah, S. Das and A. Chakravorty, Inorg. Chem., 41, 4502 (2002).
8. L. Casella and M. Gullotti, Inorg. Chem., 22, 2259 (1983)

9. R. Wagner and F. A. Walker, Inorg. Chem., 22, 3021 (1983).

10. L.L. Koh, J.O. Ranford, W.T. Robinson, J.O. Svensson, A.L.C. Tan and D.Q. Wu, Inorg. Chem., 35, 6466 (1996).

11. S. Bandyopadhyay, G.N. Mukherjee and M.G.B. Drew, Inorg. Chim. Acta, 359, 3243 (2006).

12. M. Nagarathinam, K. Saravanan, W.L. Leong, P. Balaya and J.J. Vittal, Cryst. Growth Des., 9, 4461 (2009).

13. X.D. Yang, J.D. Ranford and J.J. Vittal, Cryst. Growth Des., 4, 781 (2004).

14. O. Pouralimardan, A.C. Chamayou, C. Janiak and M.H. Hosseini, Inorg. Chim. Acta, 360, 1599 (2007).

15. C.T. Yang, M. Vetrichelvan, X.D. Yang, B. Moubaraki, K.S. Murray and J.J. Vittal, J. Chem. Soc., Dalton Trans., 113 (2004).

16. G.M. Sheldrick, SHELXS-97, Program for Crystal Structure Solution, University of Göttingen, Germany (1997).

17. G.M. Sheldrick, SHELXL-97, Program for Crystal Structure Refinement, University of Göttingen, Germany (1997).

18. P. King, R. Clerac, W. Wernsdorfer, C.E. Anson and A.K. Powell, Dalton Trans., 2670 (2004)

19. X.G. Cui, H.J. Sun, D.X. Liu, X.Y. Li and S.L. Li, Acta Chim. Sin., 51, 346 (1993).

20. X.D. Yang, D.Q. Wu, J.D. Ranford and J.J. Vittal, Cryst. Growth Des., 5, 41 (2005).

21. Z.L. Lu, D.Q. Zhang, S. Gao and D.B. Zhu, Inorg. Chem. Commun., 8, 746 (2005) 